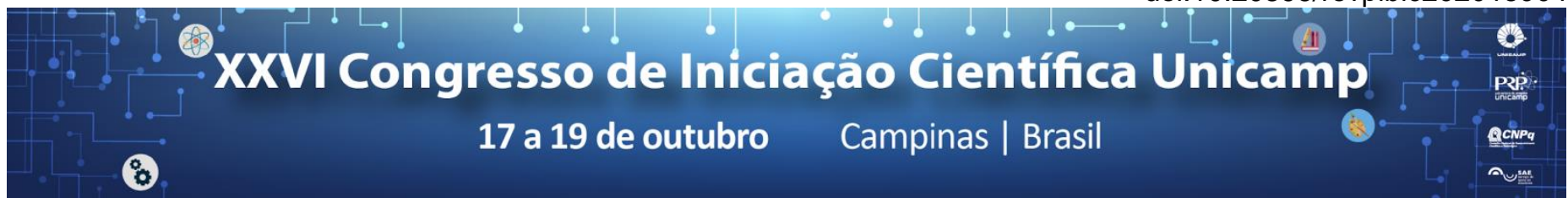

\title{
Desempenho mecânico de concreto com borracha e sílica ativa
}

\section{Lucas Silveira Batista*, Rosa Cristina Cecche Lintz}

\section{Resumo}

Esta pesquisa trata do estudo das propriedades físicas e mecânicas do concreto com adição de até $100 \%$ de borracha de pneus em substituição ao agregado miúdo natural. Analisou-se o comportamento de diferentes misturas de concreto segundo as propriedades: trabalhabilidade, resistência à compressão, resistência à tração na flexão, módulo de elasticidade, massa específica aparente no estado endurecido, índice de vazios e absorção de água. Os ensaios foram realizados de acordo com as prescrições das normas brasileiras vigentes.

Palavras-chave: Concreto, borracha, materiais alternativos.

\section{Introdução}

O uso da borracha de pneus como agregado no concreto colabora com a destinação adequada dos pneus inservíveis, além de proporcionar a redução da extração de materiais naturais. No entanto, a adição de borracha altera significativamente a resistência mecânica do concreto.

Lv et al. (2015), verificaram em seus estudos que ocorre uma redução de aproximadamente $80 \%$ na resistência à compressão quando $100 \%$ do agregado miúdo natural é substituído por borracha.

Aiello e Leuzzi (2010), observaram que a perda de resistência à compressão com substituição pela borracha de $75 \%$ do agregado graúdo foi de $61,9 \%$ e na substituição dos agregado miúdo foi de $37,1 \%$

Algumas características benéficas que a borracha proporciona ao concreto foram observadas por alguns pesquisadores, tais como: aumento na ductilidade (ALIABDO et al., 2015), redução na densidade (MOUSTAFA E ELGAWADY, 2015), melhora na absorção acústica (MEDINA et al., 2016), melhora na resistência à abrasão (SILVA et al., 2015).

Dentro deste contexto, nesta pesquisa foram produzidos concretos com substituição de $0 \%, 30 \%, 60 \%$ e $100 \%$ em massa do agregado miúdo natural por borracha de pneus e foram avaliadas as suas propriedades físicas e mecânicas.

\section{Resultados e Discussão}

Os resultados dos ensaios de resistência à compressão, tração na flexão, módulo de elasticidade e densidade aparente aos 28 dias, realizados de acordo com as normas brasileiras são apresentados na Tabela 1.

Pode-se observar que as reduções na resistência mecânica e densidade do concreto, são crescentes de acordo com o aumento da quantidade de borracha, no concreto; a borracha causou reduções na resistência à compressão de aproximadamente 52\%; 86\% e 95\% respectivamente para os concretos com substituição de $30 \%, 60 \%$ e $100 \%$ do agregado miúdo pela borracha.
Tabela 1 - Propriedades do concreto aos 28 dias de cura.

\begin{tabular}{|c|c|c|c|c|}
\hline Traços & $\mathbf{0} \%$ & $\mathbf{3 0} \%$ & $\mathbf{6 0} \%$ & $\mathbf{1 0 0 \%}$ \\
\hline $\begin{array}{c}\text { Resistência à } \\
\text { Compressão (MPa) }\end{array}$ & 97,40 & 47,00 & 13,40 & 4,80 \\
\hline Tração na Flexão (MPa) & 10,17 & 5,20 & 2,98 & 1,64 \\
\hline $\begin{array}{c}\text { Módulo de Elasticidade } \\
(\mathrm{GPa})\end{array}$ & 47,69 & 32,21 & 14,42 & 7,77 \\
\hline $\begin{array}{c}\text { Densidade aparente } \\
\left(\mathbf{g} / \mathrm{cm}^{3}\right)\end{array}$ & 2,47 & 2,28 & 1,84 & 1,69 \\
\hline
\end{tabular}

\section{Conclusões}

Diante dos resultados obtidos nesta pesquisa $e$ parcialmente demonstrados acima, pode-se concluir que a borracha de pneus, em quantidades adequadas, pode ser utilizada como um material alternativo no concreto. Nesta pesquisa notou-se que até $30 \%$ de substituição de agregado pela borracha o concreto é classificado como estrutural. O concreto com alto teor de borracha possui baixa resistência à compressão, podendo ser utilizado em locais de menor solicitação de carga, como ciclovias, quadras poliesportivas e vias para pedestres, sem função estrutural.

\section{Agradecimentos}

Ao CNPq e a Faculdade de Tecnologia - FT pelo apoio e suporte a pesquisa.

AIELLO M. A.; F. LEUZZI, Waste tyre rubberized concrete: Properties at fresh and hardened state, Waste Management, 30, 1696-1704, 2010

ALIABDO, A. A. et al., Utilization of waste rubber in non-structural applications, Construction and Building Materials 91, 195 - 207, 2015.

LV, J. et al. Effects of rubber particles on mechanical properties of lightweight aggregate concrete. Construction and Building Materials, v. 91, p. 145-149, 2015

MEDINA, N. S.; MEDINA, D. F.; OLIVARES, F. H., Influence of fibers partially coated with rubber from tire recycling as aggregate on the acoustical properties of rubberized concrete, Construction and Building Materials, v. 129, p. 25-36, 2016.

MOUSTAFA, A.; ELGAWADY, M. A. Mechanical properties of high strength concrete with scrap tire rubber. Construction and Building Materials, v. 93 , p. 249-256, 2015

SILVA, F. M. et al. Investigation on the properties of concrete tactile paving blocks made with recycled tire rubber. Construction and Building Materials, v. 91, p. 71-79, 2015. 